\title{
BIODEGRABILITY OF BIOPLASTIC MATERIALS IN A CONTROLLED COMPOSTING ENVIRONMENT
}

\author{
Magdalena Daria Vaverková', Dana Adamcová' \\ 1 Faculty of Agronomy, Mendel University in Brno, Zemědělská 1665/1, 61300 Brno, Czech Republic, e-mail: \\ magda.vaverkova@uake.cz; dana.adamcova@mendelu.cz
}

Received: 2015.03.02

Accepted: 2015.06.02

Published: 2015.07.01

\begin{abstract}
The objective of this study was to determine the biodegradability of bioplastic materials - sponge cloths - available on the European market that are labeled as $100 \%$ biodegradable but not certified as compostable. The test was carried out in a controlled composting environment. The project length was 22 weeks. The emphasis was put on discovering whether the sponge cloths are biodegradable or not. Based on the results thereof it can be concluded that sponge cloths have not decomposed completely but their color has changed and that degradation and physical changes occurred. Samples $A_{1}$, and $A_{2}$ have not decomposed completely and exhibited very slow degradation rate. Sample $\mathrm{B}_{5}$ exhibited the highest degradation rate. Samples $\mathrm{B}_{3}, \mathrm{~B}_{4}$ exhibited high degree of decomposition. The main conclusion from this study is that biodegradation of bioplastics materials strongly depends on both the environment in which they are placed and the chemical nature of the material.
\end{abstract}

Keywords: biodegradation, composting, waste treatment, controlled environment, bioplastic, sponge cloth.

\section{INTRODUCTION}

Although biodegradable polymers have been commercialized for over 30 years, this niche market is beset with a variety of roadblocks led by high prices and lack of an industrial infrastructure to deal with these materials [Baji et al. 2007, Liu et al. 2012, Pack et al. 2012, Czech et al. 2013]. On the other hand, wise utilization of bioresources is urgent regarding the emerging energy crisis and heavily environmental contaminations [Wang et al. 2008, Czech et al. 2013]. In fact, biodegradable polymers can be derived from various raw materials, such as chitosan, chitin and starch [Czech et al. 2013]. A vast number of biodegradable polymers have been synthesized recently and some microorganisms and enzymes capable of degrading them have been identified [Chandra, Rustgi 1998].

In many countries, environmental pollution by synthetic polymers has assumed dangerous proportions. As a result, attempts have been made to solve these problems by including biodegrad- ability into polymers in everyday use [Chandra, Rustgi 1998].

Biodegradation is a natural process by which organic chemicals in the environment are converted to simpler compounds, mineralized and redistributed through elemental cycles such as the carbon, nitrogen and sulphur cycles. Biodegradation can only occur within the biosphere as microorganisms play a central role in the biodegradation process [Chandra, Rustgi 1998]. Under appropriate conditions of moisture, temperature and oxygen availability, biodegradation is a relatively rapid process. Biodegradation for limited periods is a reasonable target for the complete assimilation and disappearance of an article leaving no toxic or environmentally harmful residue [Chandra, Rustgi 1998].

The respect of the environment is a capital point in a sustainable development context. We should act in this way to preserve fossil resources and reduce the pollution of the Earth. The fabrication of industrial products must consume less 
energy and the raw materials must be in priority renewable resources, in particular from agricultural origins [Lucas et al. 2008]. Therefore, biodegradable plastics and bio-based polymer products based on annually renewable agricultural and biomass feedstock can form the basis for a portfolio of sustainable, eco-efficient products that can compete and capture markets currently dominated by products based exclusively on petroleum feedstock [Mohanty et al., 2002, La Mantia, Morreale 2011].

Biodegradable polymers are useful for various applications in medical, agriculture, drug release and packaging fields [Chandra, Rustgi 1998]. Many manufacturers have introduced biodegradable bioplastic materials and have suggested that consumers avoid conventional ones. An increasing number of products labeled with the terms "environmentally friendly", "degradable", "bio-," "green-", "biobased", and "biodegradable" are being developed as promising solutions to litter "simply disappearing".

The objective of this study was to determine the biodegradability of bioplastic materials sponge cloths - available on the European market that are labeled as $100 \%$ biodegradable but not certified as compostable. The test was carried out in a controlled composting environment. The project length was 22 weeks. The emphasis was put on discovering whether the sponge cloths are biodegradable or not.

\section{MATERIAL AND METHODS}

\section{Bioplastic materials - sponge cloths}

The investigated materials were labeled as $100 \%$ biodegradable sponge cloths obtained from chain stores in the Czech Republic. Two kinds of biodegradable sponge cloths (commercially available) (Figure 1 and Figure 2) were used in this study and cellulose filter paper as a positive control (reference mixture). One of them (as stated by the manufacturer) was a sponge made from renewable resources and using an internal organic cotton mesh - samples A (Figure 1).

Another (as stated by the manufacturer) was a super absorbent sponge, easy to rinse, washable at $95^{\circ} \mathrm{C}$, durable with an internal cotton mesh, made from natural fibers - samples B (Figure 2).

The amounts of synthetic waste and sponge pieces placed in each reactor are listed in Table 1.

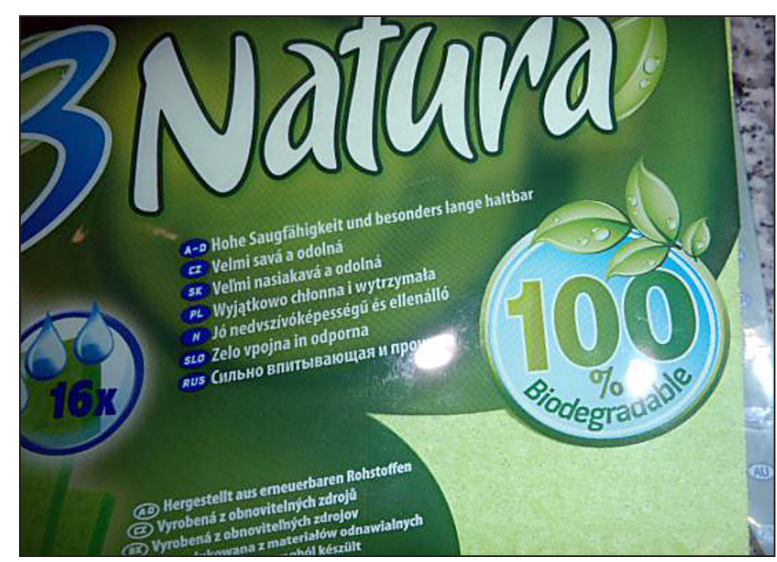

Figure 1. Biodegradable sponge cloth - samples A $\left(A_{1}, A_{2}\right)$

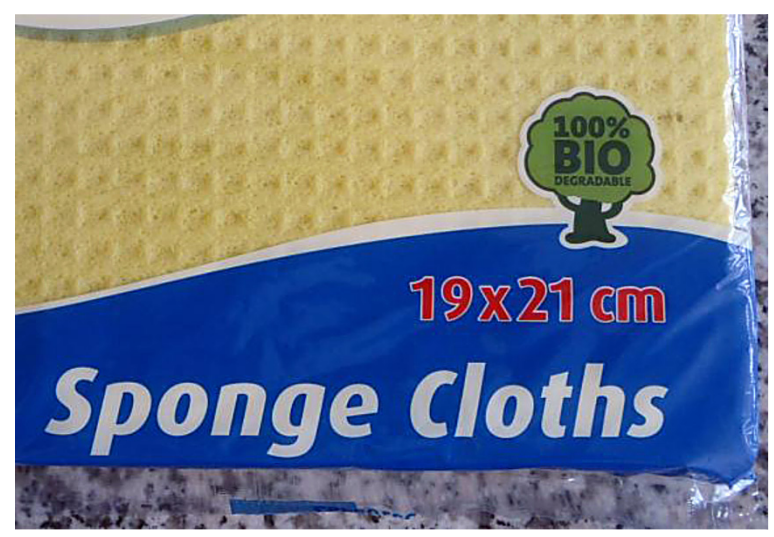

Figure 2. Biodegradable sponge cloth - samples B

\section{Disintegration tests}

The degree of disintegration of the sponge pieces was evaluated following modified version of CSN EN 14806 Norm "Packaging Preliminary evaluation of the disintegration of the packaging materials under simulated composting conditions in a laboratory scale test" and a modified version of CSN EN ISO 20200 "Plastics - Determination of the degree of disintegration of plastic materials under simulated composting conditions in a laboratory-scale test" (ISO 20200:2004). According to these tests, the sponge pieces were mixed with a solid biodegradable synthetic material and subjected to aerobic degradation. However, the composition of the synthetic material was changed as follows (as percentage of dry mass): $40 \%$ wood sawdust, $30 \%$ biodegradable municipal waste, $10 \%$ compost, $10 \%$ starch, $6 \%$ glucose, $4 \%$ oil. This modification was undertaken in order to bring the test nearer to real conditions.

For each tested material two reactors were prepared following the CSN EN 14806 Norm. 
Table 1. Amounts of synthetic waste and sponge pieces placed in each reactor

\begin{tabular}{|c|l|c|c|c|}
\hline Sample & \multicolumn{1}{|c|}{ Type } & Description & $M_{i}{ }^{*}$ sample [g] & $\mathrm{m}$ substrate [g] \\
\hline 1 & Sample A1 & $100 \%$ biodegradable & $16.0 \pm 0.5$ & $433 \pm 0.5$ \\
\hline 2 & Sample A2 & $100 \%$ biodegradable & $16.0 \pm 0.5$ & $433 \pm 0.5$ \\
\hline 3 & Sample B1 (yellow) & $100 \%$ biodegradable & $16.0 \pm 0.5$ & $433 \pm 0.5$ \\
\hline 4 & Sample B2 (yellow) & $100 \%$ biodegradable & $16.0 \pm 0.5$ & $433 \pm 0.5$ \\
\hline 5 & Sample B3 (pink) & $100 \%$ biodegradable & $16.0 \pm 0.5$ & $433 \pm 0.5$ \\
\hline 6 & Sample B4 (pink) & $100 \%$ biodegradable & $16.0 \pm 0.5$ & $433 \pm 0.5$ \\
\hline 7 & Sample B5 (blue) & $100 \%$ biodegradable & $16.0 \pm 0.5$ & $433 \pm 0.5$ \\
\hline 8 & Sample B6 (blue) & $100 \%$ biodegradable & $16.0 \pm 0.5$ & $433 \pm 0.5$ \\
\hline 9 & Cellulose (blank) & - & $16.0 \pm 0.5$ & $433 \pm 0.5$ \\
\hline
\end{tabular}

* $M_{i}$ - initial dry mass of sponge pieces.

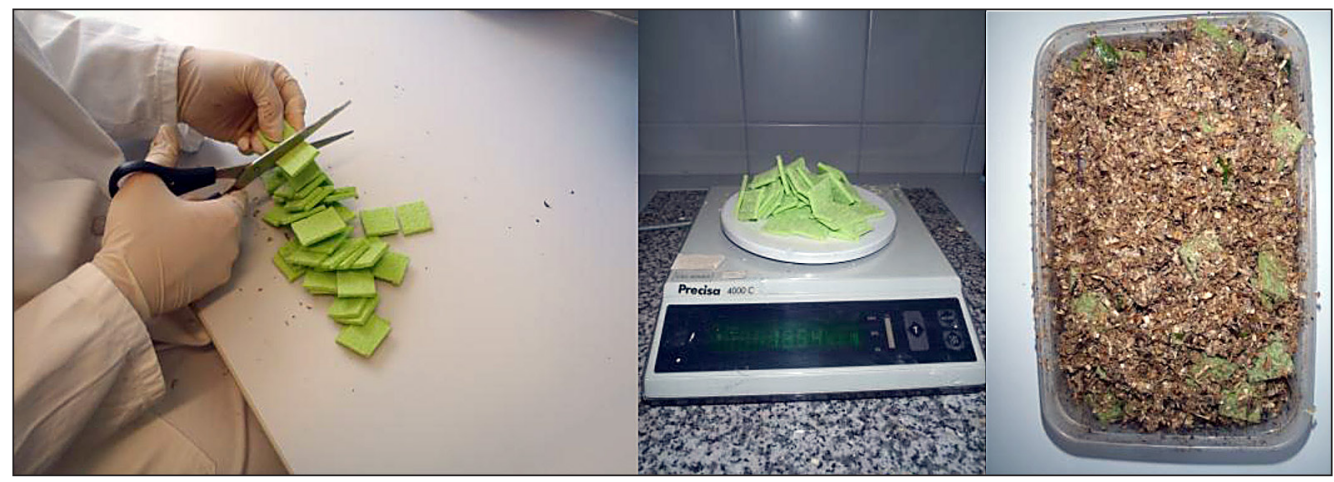

Figure 3. Sponge pieces cut into smaller ones

The CSN EN 14806 Norm states as useful for the control of the development in the reactor in which the composting takes place to undertake a blind experiment without the tested material. The authors modified the procedure stated in the Norm and in order to safeguard the presence of suitable conditions for biodegradation cellulose filter paper was used. The control of humidity was carried out under the CSN EN 14806 Norm, not according to the CSN EN ISO 20200.

The compost used corresponded to threemonth-old mature compost, which was provided by a full-scale aerobic composting plant located in Brno-Černovice (Czech Republic). The characteristics of the compost used are shown in Table 2.

The commercial compost was sieved through a $5 \mathrm{~mm}$ sieve before it was added to the mixture. The manufactured pieces were cut into smaller ones and vacuum-dried at $40.0^{\circ} \mathrm{C}\left( \pm 2^{\circ} \mathrm{C}\right)$ for $72 \mathrm{~h}$ before the experiments (Figure 3 ).

The sponge pieces and reference materials were used in the same form, that is, both had a surface of $25 \mathrm{~mm} \times 25 \mathrm{~mm}$. A mass of $16.0 \pm 0.5$ $\mathrm{g}$ of sponge pieces was mixed with $433 \cdot 10^{-3} \mathrm{~kg}$ of wet synthetic material and put in a polypropylene reactor. The polypropylene vessels of 300 $\mathrm{mm} \times 200 \mathrm{~mm} \times 100 \mathrm{~mm}$ (length, width, height)
(Figure 3) were hermetically sealed to avoid excessive evaporation, but they had $5 \mathrm{~mm}$ diameter holes at the center of each $100 \mathrm{~mm}$ side for air exchange. The initial volume of the mixture was approximately $90 \%$ of the volume of the reactor. In Table 1, the initial weights of synthetic material and the corresponding amounts of sponge pieces added to each reactor are summarized.

Table 2. Characteristics of the compost

\begin{tabular}{|c|c|c|}
\hline Parameters & Value & Unit \\
\hline Moisture & $30-65$ & $\%$ \\
\hline Combustibles & min. 20 & $\%$ \\
\hline Total nitrogen & min. 0.6 & $\% \mathrm{DM}$ \\
\hline $\mathrm{pH}$ & $6.0-8.5$ & \\
\hline Undecomposable ingredients & max. 2.0 & $\%$ \\
\hline $\mathrm{C}: \mathrm{N}$ & max. 30 & \\
\hline $\mathrm{Cd}$ & 2 & $\mathrm{mg} \cdot \mathrm{kg}^{-1}$ \\
\hline $\mathrm{Pb}$ & 100 & $\mathrm{mg} \cdot \mathrm{kg}^{-1}$ \\
\hline $\mathrm{Hg}$ & 1 & $\mathrm{mg} \cdot \mathrm{kg}^{-1}$ \\
\hline $\mathrm{As}$ & 20 & $\mathrm{mg} \cdot \mathrm{kg}^{-1}$ \\
\hline $\mathrm{Cr}$ & 100 & $\mathrm{mg} \cdot \mathrm{kg}^{-1}$ \\
\hline $\mathrm{Mo}$ & 20 & $\mathrm{mg} \cdot \mathrm{kg}^{-1}$ \\
\hline $\mathrm{Ni}$ & 50 & $\mathrm{mg} \cdot \mathrm{kg}^{-1}$ \\
\hline $\mathrm{Cu}$ & 150 & $\mathrm{mg} \cdot \mathrm{kg}^{-1}$ \\
\hline $\mathrm{Zn}$ & 600 & $\mathrm{mg} \cdot \mathrm{kg}^{-1}$ \\
\hline
\end{tabular}


The aerobic degradation was carried out in an air circulation oven (composting bioreactor) at a constant temperature of $58.0 \pm 2{ }^{\circ} \mathrm{C}$. The duration of the incubation was 22 weeks. During this time, moisture, mixing and aeration of the samples were periodically controlled. Also the $\mathrm{pH}$ was measured in order to study its evaluation. During the experiment wood sawdust was added because of $\mathrm{pH}$ adjustment (mean $20 \mathrm{~g}$ ).

After a 22-week composting period, the seven composts obtained were characterized by determining their final mass. Each compost sample was dried at $58.0 \pm 2{ }^{\circ} \mathrm{C}$ until a constant mass was obtained and then sieved with the objective of separating the remaining plastic pieces greater than $2 \mathrm{~mm}$. The recovered fragments were washed with distilled water, dried at $40.0 \pm 2{ }^{\circ} \mathrm{C}$, and weighed for calculating the corresponding disintegration degree $(D)$ :

$$
D=\frac{M_{i}-M_{r}}{M_{i}} 100
$$

where: $M_{i}-$ corresponds to the initial dry mass of sponge pieces,

$M_{r}$-represents the dry mass of the recovered sponge pieces after composting and sieving.

Monitoring of the composting process and the resulting compost products are essential to determine whether the biodegradable sponge cloths used are biodegradable/compostable and whether they have a detrimental effect on either the composting process or the compost product.

\section{RESULTS AND DISCUSSION}

\section{Monitoring and control of composting experiments}

The composting reaction was periodically controlled by measuring the temperature and odor and by determining the $\mathrm{pH}$ and the content of moisture of each reactor. Further verification of the correct course of the composting process can be conducted by means of $\mathrm{pH}$. For the observation and control of the composting substance $\mathrm{pH}$ papers were used. The monitoring was carried out regularly during the entire composting process. Figure 4 shows the $\mathrm{pH}$ variation of each reactor over time. The observed $\mathrm{pH}$ changes not always correspond to the theoretical evaluation following the Norm CSN EN 14806. Because of this during the experiment wood sawdust was added (mean 20g)_as needed.

\section{Temperature profile}

The temperature was maintained at $58.0^{\circ} \mathrm{C}$ $\left( \pm 2.0^{\circ} \mathrm{C}\right)$ as it is shown in Figure 5. During the period of composting, the temperature decreased below $56^{\circ} \mathrm{C}\left( \pm 2.0^{\circ} \mathrm{C}\right)$ because of the mixing and aeration of the samples.

The temperatures in the composting bioreactor (with air circulation) were recorded regularly during the entire course of the experiment. Despite the CSN EN 14806 Norm enables to terminate the temperature measurement after 45 days, in our experiment the temperature was measured throughout the period of 22 weeks. On the basis of the measured figures, a temperature profile was created (Figure 5).

\section{Control of humidity}

Losses of water were observed in all of the reactors throughout the composting period, distilled water was added to the reactors in order to maintain the optimal percentage of moisture. After 22 weeks of composting, each compost sample was characterized. The humidity control was conduct-

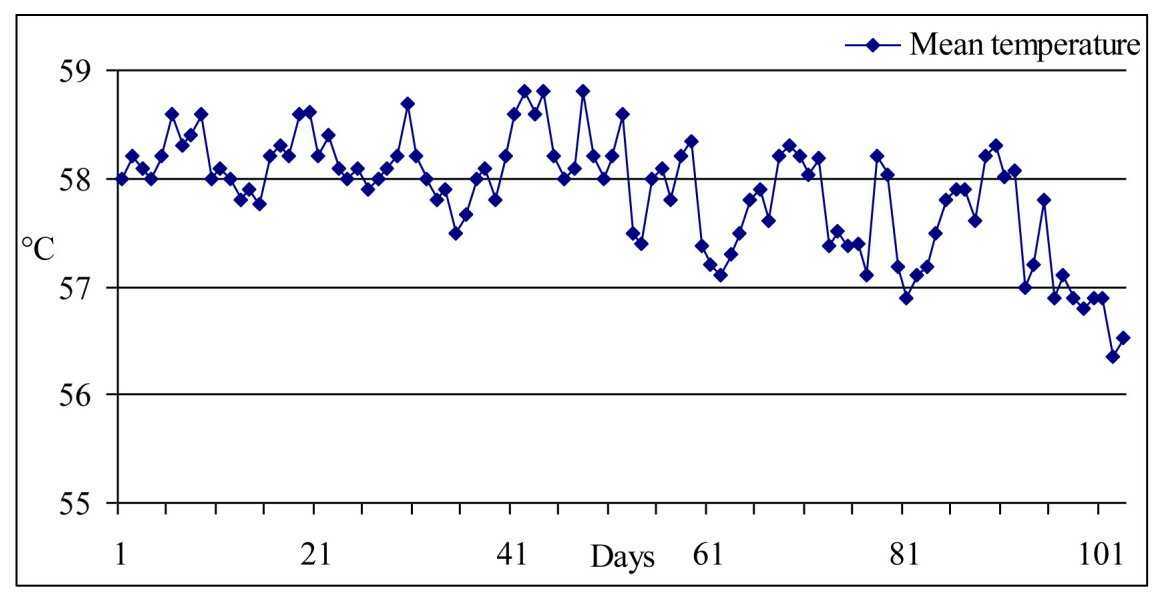

Figure 4. $\mathrm{pH}$ variation with respect to time during the composting period 


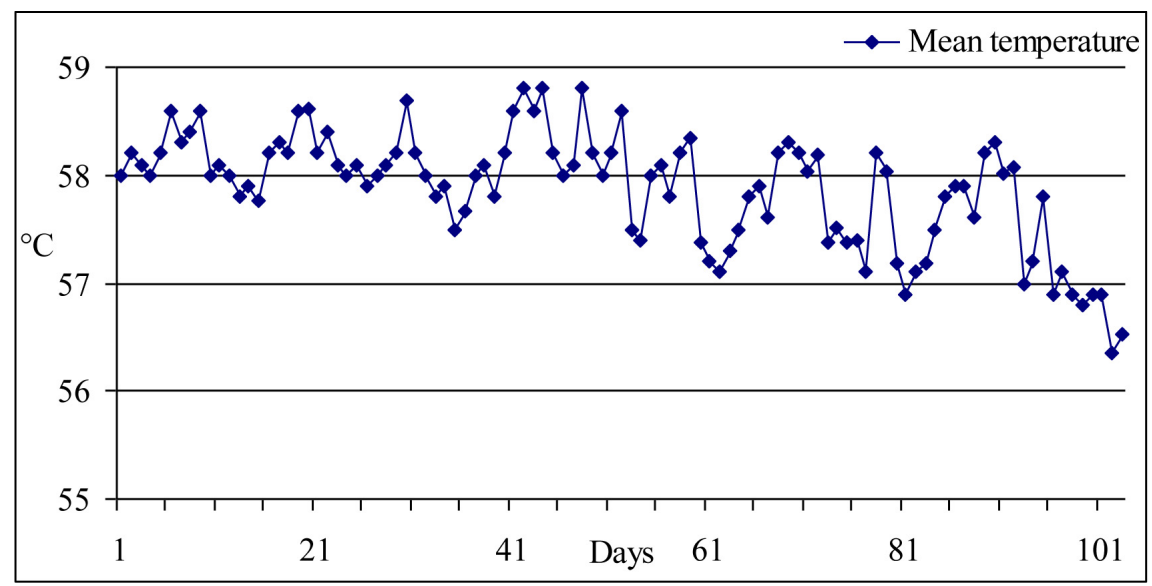

Figure 5. Mean temperature variation (sample 1-9) with respect to time during the composting period

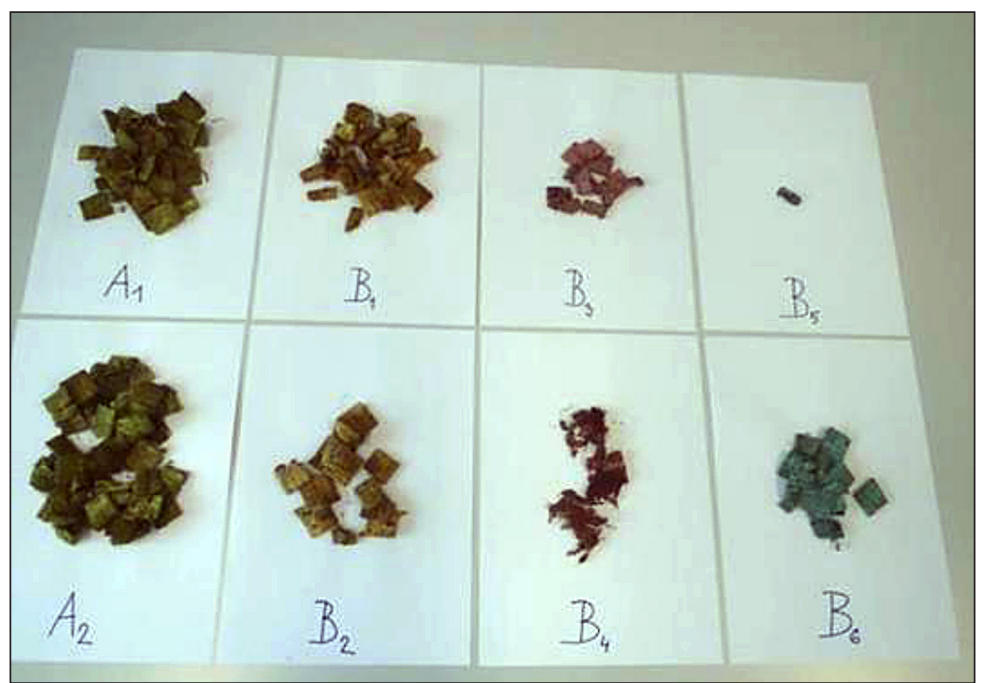

Figure 6. The sponge pieces after composting process

ed according to Kalina [Kalina, 2004]. The humidity was measured by a preliminary test periodically during the entire course of the experiment.

\section{Odor}

Odor was observed during the composting process. The sequence of recorded odors in the test was as follows: during the first two days the synthetic waste showed acid odor, approximately from day 8 the odor altered into ammonia and from day 20 no odors (ammonia or acid) were perceptible.

\section{Disintegration calculation}

Table 3 presents the exact amounts of sponge pieces before and after composting from each reactor, as well as their corresponding disintegration degree $(D)$, calculated according to Eq. (1). The sponge pieces after composting process are shown in Figure 6.
In samples $\mathrm{B}_{3}, \mathrm{~B}_{4}$ and $\mathrm{B}_{5}$, more than $80 \%$ of the initial plastic material was degraded. In particular, the disintegration degree of samples $\mathrm{B}_{5}$, had an average value of $99.5 \%$, while the average values obtained for samples $\mathrm{B}_{3}$ and $\mathrm{B}_{4}$ were $84.8 \%$ and $87.8 \%$, respectively. Sample $B_{1}, B_{2}$ and $\mathrm{B}_{6}$ showed a decomposition rate of less than $80 \%$. The lowest percentage of decomposition was observed in samples $\mathrm{A}_{1}(21.7 \%)$ and $\mathrm{A}_{2}(12.8 \%)$.

\section{CONCLUSION}

In this study, the biodegradability of two materials used for commercial applications was investigated under composting conditions. The validity of the tests was confirmed in that positive controls (cellulose paper) biodegraded by $100 \%$. While same of the bioplastic materials - sponge cloths biodegraded to an appreciable extent some did not improve the biodegradability of those recalcitrant materials. The biodegradation of the sponge cloths 
Table 3. Amounts of sponge pieces before and after composting and disintegration degree $(D)$

\begin{tabular}{|c|l|c|c|c|}
\hline Sample & \multicolumn{1}{|c|}{ Type } & $\mathrm{M}_{i}[\mathrm{~g}]$ & $\mathrm{M}_{r}[\mathrm{~g}]$ & ${\text { (D) decomposition [\%] }]^{*}}$ \\
\hline 1 & Sample A1 & $16.0 \pm 0.5$ & 12.53 & 21.7 \\
\hline 2 & Sample A2 & $16.0 \pm 0.5$ & 13.95 & 47.8 \\
\hline 3 & Sample B1 (yellow) & $16.0 \pm 0.5$ & 8.38 & 67.6 \\
\hline 4 & Sample B2 (yellow) & $16.0 \pm 0.5$ & 5.19 & 84.8 \\
\hline 5 & Sample B3 (pink) & $16.0 \pm 0.5$ & 2.42 & 87.75 \\
\hline 6 & Sample B4 (pink) & $16.0 \pm 0.5$ & 1.96 & 99.5 \\
\hline 7 & Sample B5 (blue) & $16.0 \pm 0.5$ & 0.08 & 74.4 \\
\hline 8 & Sample B6 (blue) & $16.0 \pm 0.5$ & 4.10 & 100 \\
\hline 9 & Cellulose (blank) & $16.0 \pm 0.5$ & 0.00 & \\
\hline
\end{tabular}

- labeled as $100 \%$ biodegradable but not certified as compostable (samples $\mathrm{B}_{3}, \mathrm{~B}_{4}$ and $\mathrm{B}_{5}$,) proceeded very well. After 22 weeks of composting in the laboratory-scale test, the different test materials seemed to disappear (sample $\mathrm{B}_{5}$ seemed to disappear completely). This was confirmed at the end of the test. The mass of sample $B_{4}$ was measured to be $1.96 \mathrm{~g}$ after finishing the test, while the mass of sample $B_{5}$ was measured to be $0.08 \mathrm{~g}$. From this test, it can be concluded that the sponge cloths (Samples B) showed a high level of biodegradation during the 22-week composting laboratory-scale test. However, Samples A - sponges made from renewable resources and using an internal organic cotton mesh showed very slow degradation rate. The weight loss of these samples was $3.47 \mathrm{~g}$ and $2.05 \mathrm{~g}$. The main conclusion from this study is that biodegradation of bioplastics materials strongly depends on both the environment in which they are placed and the chemical nature of the material.

Systematic research to investigate the effects of composting conditions on the degradability of biodegradable materials should be performed in the future.

\section{REFERENCES}

1. Baji A., Wong S.C., Liu T.X., Li T.C., Srivatsan T.S. 2007. Morphological and X-ray diffraction studies of crystalline hydroxyapatite-reinforced polycaprolactone. J. Biomed. Mater. Res. B., 81B, 343-350.
2. Liu W.Q., Budtova T. 2012. Ionicliquid: a powerful solvent for homogeneous starch- cellulose mixing and making films with tuned morphology. Polymer, 53, 5779-5787.

3. Pack S., Bobo E., Muir N., Yang K., Swaraj S., Ade H., Cao Ch., Korach Ch.S., Kashiwagi T., Rafailovich M.H. 2012. Engineering biodegradable polymer blends containing flame retardant-coatedstarch/nanoparticles. Polymer, 53, 4787-4799.

4. Czech Z., Wilpiszewska K., Tyliszczak B., Jiang X., Bai Y., Shao L. 2013. Biodegradable self-adhesive tapes with starch carrier. Int. J. Adhes Adhes., 44, 195-199.

5. Wang J.P., Chen Y.Z., Zhang S.J., Yu H.Q. 2008. A chitosan-based flocculant prepared with gammairradiation-induced grafting. Bioresource Technol., 99, 3397-3402.

6. Chandra R., Rustgi R. 1998. Biodegradable polymers. Prog. Polym Sci., 23, 1273-1335.

7. Lucas N., Bienaime Ch., Belloy Ch., Queneudec M., Silvestre F., Nava-Saucedo J.E. 2008. Polymer biodegradation: Mechanisms and estimation techniques - A review. Chemosphere, 73 (4), 429-442.

8. Mohanty A.K., Misra M., Drzal L.T. 2002. Sustainable bio-composites from renewable resources: Opportunities and challenges in the green materials world. J. Polym Environ., 10 (1/2), 19-26.

9. La Mantia F.P., Morreale M. 2011. Green composites: A brief review. Composites Part A: Applied Science and Manufacturing, 42 (6), 579-588.

10. Kalina M. 2004. Composting and care for land. Grada Publishing, Prague 2004 [in Czech]. 